\title{
PRIVATE DIARY AS A CHAMBER DOCUMENT: DISCOURSE PECULIARITIES
}

\author{
Grigory V. Tokarev \\ Tula State Lev Tolstoy Pedagogical University, Tula, Russia
}

\begin{abstract}
The diary is presented as a type of a chamber document that is referred to a type of autocommunication, communication limited to one person or a small group of people. The diary is viewed as a fixation of impressions and ideas and a source of information about its writer. It is obvious that the completed diary can be viewed as a document, an evidence of something. The possibilities of studying the diary in synchronic and diachronic, real and potential aspects are demonstrated from the perspective of the writer and the reader. It is stated that in the real dimension the diary does not have limitation, completeness or integrity, it possesses these attributes in potential measurement because its writer does not know how the events can unfold. However, the diary has a certain plot for its reader. The author reveals such signs of the diary as literary rawness, unpreparedness, and iconicity, defines its main functions: accumulative, cognitive-generating, compensatory, regulating. The article explains that the objectivity of the diary entry is expressed in the fact that it conveys the writer's way of thinking and feeling with documentary accuracy, but the writer's point of view is not an objective interpretation of anything. The peculiarity of the setting (space and timeline) in the diary is in its linearity, which determines the specificity of the diary division on the chronological principle. Leo Tolstoy's diary is of a particular interest for the study of chamber documents.
\end{abstract}

Key words: personal discourse, text, chamber document, diary, auto-communication, Leo Tolstoy.

Citation. Tokarev G.V. Private Diary as a Chamber Document: Discourse Peculiarities. Vestnik Volgogradskogo gosudarstvennogo universiteta. Seriya 2. Yazykoznanie [Science Journal of Volgograd State University. Linguistics], 2019, vol. 18, no. 2, pp. 48-56. (in Russian). DOI: https://doi.org/10.15688/jvolsu2.2019.2.5

\section{ДИСКУРСИВНЫЕ ОСОБЕННОСТИ ЛИЧНОГО ДНЕВНИКА КАК КАМЕРНОГО ДОКУМЕНТА}

\author{
Григорий Валериевич Токарев \\ Тульский государственный педагогический университет им. Л.Н. Толстого, г. Тула, Россия
}

\begin{abstract}
Аннотация. Дневник рассмотрен как вид камерного документа, функционирующего в индивидуальном общении, ограниченном одним человеком или небольшой группой лиц, ориентированном прежде всего на автокоммуникацию. Поскольку в дневнике фиксируются впечатления и мысли создающего субъекта, он является источником информации о писавшем. Из этого следует, что завершенные дневниковые записи можно трактовать как документ, свидетельство чего-либо. Продемонстрированы возможности изучения дневника в синхроническом и диахроническом, реальном и потенциальном аспектах, с позиции пишущего и читающего. Установлено, что в реальном измерении он не обладает отграниченностью, завершенностью, цельностью, поскольку его автор не знает, как могут разворачиваться собы๓ं тия. Этими признаками дневник обладает в потенциальном измерении, где для читающего он представляет некую фабулу. Выявлены признаки дневника: литературная необработанность, неподготовленность, иконичность, идиоматичность, конспиративность, линейность, членимость. Определены его основные функции: аккумулирующая, когнитивно-генерирующая, компенсаторная, регулирующая. Сделан вывод о том, что объективность дневниковой записи выражается в документальной точности передачи мыслей
\end{abstract}


и чувств пишущего. При этом точка зрения пишущего не является объективной интерпретацией чеголибо. Особенностью хронотопа в дневнике является линейность, детерминирующая специфику его членимости, в основе которой лежит хронологический принцип. Исследование выполнено на материале личных дневников Л.Н. Толстого.

Ключевые слова: личностный дискурс, текст, камерный документ, дневник, автокоммуникация, Л.Н. Толстой.

Цитирование. Токарев Г. В. Дискурсивные особенности личного дневника как камерного документа // Вестник Волгоградского государственного университета. Серия 2, Языкознание. - 2019. - Т. 18, № 2. C. 48-56. - DOI: https://doi.org/10.15688/jvolsu2.2019.2.5

\section{Введение}

Одной из актуальных задач документалистики является расширение эмпирического материала за счет изучения так называемых периферийных текстов, не обладающих основными признаками документа. К таким письменным объектам можно отнести личные дневники. Они представляют большой интерес для ученых разных областей знания: этнографов, историков, культурологов, филологов и др. Данный жанр коммуникации является мало исследованным, однако в науке уже осуществлены попытки включения дневника в текстовую систему и установления его места в ней. Эскизно описаны коммуникативные, структурно-семантические, когнитивные и др. особенности данного типа текстов. Для определения феномена дневникового текста используются разнообразные термины: «эго-текст» [Михеев, 2007], «мнемоническое повествование» [Гинзбург, 1999], «наивная литература» [Арустамова, Виноградова, 2015] и др. Предприняты попытки классификации дневников в соответствии со сферой функционирования записи, ее целью, формой и т. д. М.Ю. Михеев к дневниковой прозе относит произведения разнообразных жанров: записные книжки, черновики, записи в альбомах и др. [Михеев, 2007]. В поле зрения исследователей оказываются не только дневники на традиционном, бумажном, носителе, но и сетевые дневники, живые журналы [Зализняк, 2010; Косарева, 2008,]. Особое внимание уделяется языковой специфике данного типа текстов как формы выражения идиостиля [Кубайдулова, 2015]. При этом дневники еще не были предметом специального рассмотрения в документоведческом аспекте.
Цель данной статьи - с позиций дискурсивного подхода охарактеризовать личный дневник как особый документный жанр.

\section{Методика исследования}

Признаки личного дневника и его специфика как документального жанра устанавливаются в реальном (на этапе написания) и потенциальном (на этапе прочтения) измерениях с позиции пишущего и читающего.

При толковании понятия «документ» в синхроническом аспекте акцент делается на сфере функционирования текста: он трактуется как элемент деловой коммуникации. Ср.: «Официальный документ - документ, созданный организацией, должностным лицом или гражданином, оформленный в установленном порядке» (ГОСТ Р 7.0.8-2013). При рассмотрении в диахроническом аспекте - на функции: фиксация чего-либо. В синхроническом аспекте (реальном измерении) дневник, строго говоря, нельзя отнести к документам, поскольку он не является формой делового общения. При этом дневниковые записи - это фиксация впечатлений и представлений создающего субъекта, источник, позволяющий извлечь информацию о писавшем и понять, как он себя идентифицирует. Из этого следует, что завершенный дневник (потенциальное измерение) можно рассматривать как документ, свидетельство чего-либо. Информация, содержащаяся в текстах данного коммуникативного жанра, подтверждает реальность какихлибо событий, отражает рефлексию субъекта над действительностью. Выполнение функции фиксирующего текста позволяет определить дневник как особый вид документа. Он входит в группу камерных текстов, под которыми мы понимаем инструменты индивидуальной коммуникации, ограниченной одним 
человеком или небольшой группой лиц. Рассмотрим дискурсивные особенности данного вида документа.

\section{Результаты и обсуждение}

Особый интерес для исследования представляет дневник Льва Николаевича Толстого. Это самое большое произведение, созданное писателем. Он начал его в 1847 году. Дневниковое наследие писателя составляет 13 томов в полном собрании сочинений. Толстой вел дневник 63 года.

Характерно, что первые дневниковые записи писателя отражают ориентированность автора на читателя: в них содержится немало нравоучительных элементов. Все это напоминает диалог пишущего со своим поколением. Уже в двадцатилетнем возрасте у Толстого намечается противопоставление себя обществу, неприятие сложившихся культурных установок, морализация: «...беспорядочная жизнь, которую большая часть светских людей принимает за следствие молодости, есть ничто иное, как следствие раннего разврата души...» (Толстой, т. 46, с. 3). Однако постепенно дневник писателя становится формой записей для самого себя. И.И. Загидуллина и М.Ю. Михеев отмечают: «Ведение дневника, то есть текста, обращенного к самому себе, непосредственно связано с проблемой сознания, точнее, самосознания, а эволюция дневника как жанра обусловлена процессом самоопределения человека по векторам "я" и история, “я" и государство, "я” и общество» [Загидуллина, 2009, с. 142]. Л.Н. Летягин объясняет мотив ведения дневниковых записей развитым чувством подотчетности [Летягин, 2008, c. 66].

Главная коммуникативная особенность дневника заключается в автокоммуникации, то есть сообщении самому себе. «Это все случаи, когда человек обращается к самому себе, в частности, те дневниковые записи, которые делаются не с целью запоминания определенных сведений, а имеют целью, например, уяснение внутреннего состояния пишущего, уяснение которого без записи не происходит» [Лотман, 2000, с. 164]. С.В. Волошина относит дневник к форме выражения автобиографического дискурса [Волошина, 2014, с. 261]. Свое понимание дневника в художественной форме Толстой вложил в уста главного героя романа «Воскресение» Нехлюдова: «Два года не писал дневника и думал, что никогда уже не вернусь к этому ребячеству. А это было не ребячество, а беседа с собой, с тем истинным, божественным собой, которое живет в каждом человеке» (Толстой, т. 32, c. 129). Ведение дневниковых записей для писателя было важной частью программы нравственного самосовершенствования, поиска смысла жизни, божественного начала в себе и других. В дневнике он как бы раздваивается: себе, сущему, ставит задачи, критикует себя должный Толстой.

Дневниковые записи являются формой самоидентификации личности, то есть объяснения самому себе, кто я есть. Проблема языковой объективации процесса самоосознания поставлена в трудах Н.В. Амяги [1991], М.В. Архиповой [2012], И.С. Кона [1984], Е.В. Леоновой [2014] и др. «Дневник - жанр, наиболее приспособленный, как будто созданный именно для самоидентификации, то есть это такой текст, который, в отличие от всех других эго-документов, может существовать только для автора» [Лаппо, 2018, с. 245].

Для исследования самоидентификации Толстого интересна запись от 7 июля 1854 года. В двадцатишестилетнем возрасте писатель задается вопросом: «Что я такое?». Он пытается дать себе всестороннюю объективную оценку в социальном и личностном аспектах. Записи, с одной стороны, отражают стремление пишущего пожалеть себя: «Один из 4-х сыновей отставного Подполковника, оставшийся с семилетнего возраста без родителей под опекой женщин и посторонних, не получивший ни светского, ни ученого образования и вышедший на волю 17-ти лет, без большого состояния, без всякого общественного положения и, главное, без правил; человек, расстроивший свои дела до последней крайности, без цели и наслаждения проведший лучшие годы своей жизни, наконец изгнавший себя на Кавказ, чтобы бежать от долгов и, главное, от привычек...» (Толстой, т. 47, с. 8-9). Эта речевая тактика самозащиты детерминируется желанием пишущего объяснить отрицательные черты своего характера: «Я дурен собой, неловок, необразован и светски не- 
чистоплотен. - Я раздражителен, скучен для других, нескромен, нетерпим ... и стыдлив, как ребенок. - Я почти невежда. ... - Я не воздержен, нерешителен, непостоянен, глупотщеславен и пылок, как все бесхарактерные люди. Я не храбр. Я неаккуратен в жизни и так ленив, что праздность сделалась для меня почти неодолимой привычкой. - Я умен, но ум мой еще никогда ни на чем не был основательно испытан. У меня нет ни ума практического, ни ума светского, ни ума делового. Я честен, то есть я люблю добро... Да, я не скромен; оттого то я горд в самом себе, а стыдлив и робок в свете» (Толстой, т. 46, с. 8-9). С другой стороны, перечисляя качества своего характера, Толстой называет только отрицательные аспекты. Немногие положительные - ум и скромность - рассматриваются также в отрицательном контексте. Тем самым писатель культивирует в себе комплекс неполноценности, заниженной самооценки. Именно это становится отправной точкой в индивидуальной программе самосовершенствования. Записи отражают внутреннюю дисгармонию, угрызения совести и самоуничижение: «Удивительно, как я гадок и как вовсе несчастлив и сам себе противен» (Толстой, т. 47, с. 48). Для самохарактеризации Толстой использует сниженную лексику: скотина (Толстой, т. 47, с. 105), свинья (Толстой, т. 47, с. 144), дрянь (Толстой, т. 47, с. 148). Себя писатель описывает как человека развратного, лживого, тщеславного, трусливого: «Я имел несколько раз женщин, лгал, тщеславился и, что всего ужаснее, под огнем вел себя не так, как надеялся от самого себя» (Толстой, т. 47, с. 4).

В процессе самоидентификации важную роль играет соотнесение себя с другими людьми, реакция на их слова и поведение. Так, Толстой не находит для себя ничего близкого в речи Наполеона: «Читал речь Наполеона с неописанным отвращением...» (Толстой, т. 47, c. 132); ему чуждо светское общество, несмотря на применение тактик самоуничижения, он дает себе более высокую оценку, не желает быть таким, как его ровесники: «Молодежь в галстучках меня дичится. ... Я бы лучше желал быть без носа, вонючим, зобастым, самым страшным кретином, отвратительнейшим уродом, чем таким моральным уродом» (Толстой, т. 47, с. 7).
Дневник создается с разными целями. Для каждого из пишущих они свои. Это отражается в особенностях ведения дневниковых записей: постоянно или время от времени. Толстой считал необходимым ведение дневника и так определял его цели:

1) следить за нравственным саморазвитием и влиять на этот процесс: «Теперь же, когда я занимаюсь развитием своих способностей, по дневнику я буду в состоянии судить о ходе этого развития. - В дневнике должна находиться таблица правил, и в дневнике должны быть тоже определены мои будущие деяния» (Толстой, т. 46, с. 29). При этом Толстой осмысляет сложность достижения поставленной задачи: «Интересно было бы описать ход своего морального развития, но не только слова, но мысль даже недостаточна для этого» (Толстой, т. 46, с. 102);

2) составлять план своих действий: «...так как я нахожу необходимость определять все занятия вперед, то для этого тоже необходим дневник. Хотелось бы привыкнуть определять свой образ жизни вперед, не на один день, а на год, на несколько лет, на всю жизнь... » (Толстой, т. 46, с. 34);

3) анализировать прошлое: «Последние три года, проведенные мною так беспутно, иногда кажутся мне очень занимательными, поэтическими и частью полезными; постараюсь пооткровеннее и поподробнее вспомнить и написать их» (Толстой, т. 46, с. 34);

4) вести «отчет каждого дня, с точки зрения тех слабостей, от которых хочешь исправиться» (Толстой, т. 46, с. 47).

В дневниковых записях автор намечает три раздела: правила, познания, наблюдения. Сразу отметим, что дневник отражает незаурядные писательские способности автора. На наш взгляд, раскрыть их помогли поездки Толстого на Кавказ и в Крым. Писатель отмечает национальный колорит, точно характеризует своих сослуживцев, выступает мастером диалогов, повествования небольших историй, описания внутренних состояний. Именно на страницах дневника рождается будущий великий художник. И.Ф. Салманова отмечает: «Постигая природу своего внутреннего Я, Толстой превращает этот процесс в некий универсальный метод (принцип) осмысления “другого” как внутри, так и вне себя» 
[Салманова, 2017, с. 39]. Цели дневника позволяют обнаружить главную особенность сознания Толстого - склонность к аналитизму, желание полностью контролировать свои действия. По заметкам девятнадцатилетнего автора совершенно ясно, что их создавала нестандартная во всех отношениях личность.

Публичные люди отдают себе отчет в том, что их дневниковые записи будут обнародованы, поэтому в них усматривается ориентация на читателя. Так, еще при жизни Толстого его помощники, дети, биографы обращались к дневникам писателя, например, при собирании материалов для жизнеописания гения. В последние годы жизни писателя развернулась борьба за его дневниковые записи между С.А. Толстой и В.Г. Чертковым. С 29 июля 1910 г. писатель начинает вести дневник для самого себя и дает и ему название, в котором подчеркивается осмысление того, что дневник может быть предназначен не только другим, но и себе. Именно его Толстой называет настоящим: «Начинаю новый дневник, настоящий дневник для одного себя...» (Толстой, т. 58, с. 129).

На страницы этого дневника попали записи писателя, преимущественно связанные с переживаем семейного конфликта - с женой и сыновьями. Последняя же запись в нем сделана его дочерью А.Л. Толстой со слов великого творца в последние часы его жизни.

Обратимся к описанию специфических черт дневника. Для него характерны литературная необработанность, неподготовленность, иконичность, проявляющаяся в том, что пишущий использует разнообразные сокращения, понятные только ему. Так, в последние годы жизни Толстой употреблял сокращение Е.Б.Ж., которое расшифровывается как если будем живы. Это придает дневнику признаки идиоматичности и конспиративности.

Признаки дневника как текста могут поразному проявлять себя в реальном и потенциальном измерении. Так, в реальном измерении дневниковые записи не обладают отграниченностью, завершенностью, цельностью. Эти признаки могут быть приписаны дневнику в потенциальном измерении при рассмотрении его как законченного текста. Пишущий не знает, как могут разворачиваться события. Для читающего дневник представляет опре- деленную фабулу. Ю.В. Матвеева отмечает: «...если воспринимать... письма и дневники как некую целостность, читать их от начала и до конца “насквозь”, то невольно улавливается наличие такого же точно лейтмотивного рисунка, как в мемуарах, биографиях и автобиографиях. Только механизм возникновения этих устойчиво повторяющихся мотивов принадлежит в этом случае реальности затекстовой, которая не дана читателю никак иначе, нежели в преломлении автора» [Матвеева, 2014, c. 8].

Экстралингвистические факторы (у Толстого, например, это пребывание в больнице в молодом возрасте и последние дни жизни на станции Остапово) получают текстообразующую роль. Они оформляют содержательные границы дневника как завершенного текста: для пишущего он не завершен, читающим воспринимается как законченная форма. Е.С. Чистикова в качестве типологического признака дневника называет временную удаленность [Чистикова, 2015]. Нарративный прогресс для читающего формирует ожидание развертывания событий. Пишущий не знает, когда обратится к дневнику. Дневник полностью обусловлен внешними факторами. Стимулом для записи становится реальное событие.

Дневниковые записи являются результатом субъективного переживания внешнего стимула. Читающему дневник дает достоверную информацию о личности писавшего. Объективность дневниковой записи выражается в документальной точности при передаче образа мыслей и чувств пишущего, его системы ценностей, уровня интеллектуального и нравственного развития, особенностей эмоциональной реакции на внешние стимулы. При этом точка зрения пишущего не является объективной интерпретацией чего-либо. В отношении личности Толстого, а также близких ему людей следует отметить, что попытка реконструировать объективную картину события была предпринята в книге «Любовь и бунт», в которой приводятся дневниковые записи восприятия одного события разными лицами: С.А. Толстой, Л.Н Толстым и др. (Толстая, 2013).

В потенциальном измерении дневник представляет собой завершенный текст, по которому можно восстановить цепочку собы- 
тий, специфика фиксации которых обусловлена индивидуальными факторами. Это может быть подробное или эскизное их описание, а иногда только переживание. Безусловно, дневник может сочетать все перечисленные черты. Записи Толстого в этом отношении неоднородны. Те, что были сделаны писателем в молодые годы, представляют в большей степени рефлексию на события, а также своеобразный план самосовершенствования: «1) Изучить весь курс юридических наук, нужных для окончательного экзамена в университете. 2) Изучить практическую медицину и часть теоретической. 3) Изучить языки: французский, русский, немецкий, английский, итальянский и латинский. 4) Изучить сельское хозяйство, как теоретическое, так и практическое. 5) Изучить историю, географию и статистику. 6) Изучить математику, гимназический курс. 7) Написать диссертацию. 8) Достигнуть средней степени совершенства в музыке и живописи. 9) Написать правила. 10) Получить некоторые познания в естественных науках. 11) Составить сочинения из всех предметов, которые буду изучать» (Толстой, т. 46, с. 31).

Позже дневники перерастают в хронологию мыслей, хотя признаки других типов дневниковых записей также представлены. Например, запись от 2 января 1910 г.: «Опять поправлял Сон. Уехали Ландовски. Ездил верхом. Был у Марии Александровны и Буланже. Не переставая стыдно за свою жизнь» (Толстой, т. 58, с. 3) - содержит фактуальную, эмотивную и концептуальную информацию: первые четыре предложения из приведенной записи отражают изложение фактов, последнее выражает эмоциональное состояние и дает оценку собственному мироощущению. Дневник предназначен в первую очередь для передачи фактуальной информации. В ходе анализа содержания дневниковых записей Толстого мы заметили, что в разные годы писатель менял их характер. Так, в дневниках 1854-1857 гг. пишущий в большей мере просто фиксирует прошедшие события, 1910 г. излагает свои мысли и чувства. Концептуальная и эмотивная информация, как правило скрытая в подтексте, в дневнике эксплицирована автором записи. Он выражает свои мысли и чувства открыто. Читатель дневника может сделать выводы об эмоциональном со- стоянии пишущего, влиянии экстралингвистического контекста на его мысли и т. п.

Рассмотрение дневника в реальном и потенциальном измерениях позволяет установить особенность его хронотопа - линейность. «В текстах мнемонического повествования “свобода выражения" сочетается с "несвободой вымысла, ограниченного действительно бывшим"» [Гинзбург, 1999, с. 118]. Линейность, в свою очередь, определяет специфику членимости дневника, в основе которой лежит хронологический принцип: дни - месяцы годы [Криволапова, 2012]. Дата и иногда указание на место написания, помимо самого текста, являются единственными реквизитами дневника.

\section{Заключение}

Дневник представляет собой камерный документ, предназначенный для автокоммуникации. Данный письменный жанр может быть охарактеризован в реальном и потенциальном измерении с позиции создающего и читающего. Специфика дневника формируется рядом признаков: литературной необработанностью, неподготовленностью, иконичностью, идиоматичностью, конспиративностью, линейностью, членимостью, детерминированными особенностями хронотопа. Его текст отражает фактуальную (обусловленную экстралингвистическими факторами), концептуальную и эмотивную информацию. Отдельные признаки данного жанра проявляют себя в потенциальном измерении - отграниченность, завершенность, цельность.

Цели дневника определяют его функции, к числу которых можно отнести:

1) аккумулирующую, сохраняющую в памяти какие-либо мысли, переживания, события;

2) когнитивно-генерирующую, способствующую порождению мыслей;

3) компенсаторную, позволяющую пишущему психологически разрядиться;

4) регулирующую, заключающуюся в том, что дневниковые записи дают возможность оценивать прошлое и планировать будущее.

Дневник фиксирует информацию о создающем его субъекте, выступает формой самоидентификации личности. 


\section{СПИСОК ЛИТЕРАТУРЫ}

Амяга Н. В., 1991. Самораскрытие и самопредъявление личности в общении // Личность. Общение. Групповые процессы : Современные направления теоретических и прикладных исследований в зарубежной психологии : сб. обзоров / редкол.: О. А. Власова [и др.]. М. : ИНИОН. С. 10-18.

Арустамова А. А., Виноградова К. В., 2015. Дневник К.В. Ивановой: автор и текст // Филологические заметки. Т. 1, № 13. С. 247-253.

Архипова М. В., 2012. Психологические свойства и представления, связанные с практикой ведения личного дневника // Вестник Русской христианской гуманитарной академии. Т. 13, № 3. C. 197-207.

Волошина С. В., 2014. Коммуникативная стратегия самопрезентации в автобиографическом дискурсе // Вестник Иркутского государственного техническогоуниверситета. № 9 (92). С. 261-265.

Гинзбург Л. Я., 1999. О психологической прозе. М. : Intrada. $415 \mathrm{c}$.

ГОСТ Р 7.0.8-2013. Делопроизводство и архивное дело. Термины и определения : утв. Приказом Росстандарта от 17.10.2013 № 1185-ст. М. : Стандартинформ. $12 \mathrm{c}$.

Загидуллина И. И., 2009. Михеев М.Ю. Дневник как эго-текст (Россия, XIX-XX). М. : «Водолей Publishers», 2007. 264 c. // Уральский исторический вестник. № 3 (24). С. 142-144.

Зализняк А. А., 2010. Дневник: к определению жанра // Новое литературное обозрение. № 6 (106). C. $162-171$.

Кон И. С., 1984. В поисках себя. Личность и ее самосознание. М. : Политиздат. 336 с.

Косарева М. А., 2008. Сетевой дневник в контексте теории текста (к постановке проблемы) // Вестник Читинского государственного университета. № 1 (46). С. 69-74.

Криволапова Е. М., 2012. К вопросу о генезисе жанра дневника // Ученые записки: электронный научный журнал Курского государственного университета. № 1 (21). С. 188-196.

Кубайдулова А. Ю., 2015. Дневник К.И. Чуковского: к вопросу о художественном своеобразии // Вестник Самарского государственного университета. № 2. С. 120-125.

Лаппо М. А., 2018. Самоидентификационный дискурс русской элитарной языковой личности : дис. ... д-ра филол. наук. Новосибирск. 515 с.

Леонова Е. В., 2014. Когнитивный механизм интериоризации в дневниковом дискурсе // Известия Саратовского университета. Новая серия. Серия: филология, журналистика. Т. 14, № 1. C. 34-38.
Летягин Л. Н., 2008. Личный дневник: самосознание жанра // Известия Российского государственного педагогического университета им. А.И. Герцена. № 56. С. 56-67.

Лотман Ю. М., 2000. Семиосфера. СПб. : Искусство СПб. $704 \mathrm{c}$.

Матвееева Ю. В., 2014. Проблема сюжета в документальной, биографической и автодокументальной прозе // Сюжетология и сюжетография. № 2. С. 3-19.

Михеев М. Ю., 2007. Дневник как эго-текст (Россия, XIX-XX). М. : Водолей Publishers. 264 c.

Салманова И. Ф., 2017. Исповедально-диалогическая природа автобиографического дискурса Л.Н. Толстого // Наука. Искусство. Культура. № 1 (13). C. 38-43.

Чистикова Е. С., 2015. Мнемонические тексты дневников и мемуаров: временная удаленность как типологический критерий // Вестник Ленинградского государственного университета им. А.С. Пушкина. Т. 1, № 3. С. 134-140.

\section{ИСТОЧНИКИ}

Толстая - Толстая С. Любовь и бунт. Дневник 1910 года. М. : КоЛибри : Азбука-Аттикус, $2013.416 \mathrm{c}$.

Толстой - Толстой Л. Н. Полное собрание сочинений : в 90 т. М. : Российская государственная библиотека, 2006. Т. 32 ; Т. 46 ; Т. 47 ; Т. 58.

\section{REFERENCES}

Amyaga N.V., 1991. Samoraskrytie i samopredyavlenie lichnosti v obshchenii [Self-Disclosure and SelfPresentation of a Person in Communication]. Lichnost. Obshchenie. Gruppovye processy: Sovremennye napravleniya teoreticheskikh $i$ prikladnykh issledovaniy $v$ zarubezhnoy psikhologii: sb. obzorov [Personality. Communication Group Processes: Modern directions of Theoretical and Applied Research in Foreign Psychology. Collected Reviews]. Moscow, INION, pp. 10-18.

Arustamova A.A., Vinogradova K.V., 2015. Dnevnik K.V. Ivanovoy: avtor i tekst [Diary of K.V. Ivanova: Author and Text]. Filologicheskie zametki [Philological Studies], vol. 1, no. 13, pp. 257-253.

Arkhipova M.V., 2012. Psikhologicheskie svoystva i predstavleniya, svyazannye s praktikoy vedeniya lichnogo dnevnika [Psychological Properties and Representations Relating to the Practice of Keeping a Personal Diary]. Vestnik 
Russkoy khristianskoy gumanitarnoy akademii [Journal of the Russian Christian Academy for the Humanities], vol. 13, no. 3, pp. 197-207.

Voloshina S.V., 2014. Kommunikativnaya strategiya samoprezentatsii v avtobiograficheskom diskurse [Communicative Self-Presentation Strategy in Autobiographical Discourse]. Vestnik Irkutskogo gosudarstvennogo tekhnicheksogo universiteta [Proceedings of Irkutsk State Technical University], no. 9 (92), pp. 261-265.

Ginzburg L.Ya., 1999. O psikhologicheskoy proze [On Psychological Prose]. Moscow, Intrada Publ. $415 \mathrm{p}$.

GOST R 7.0.8-2013. Deloproizvodstvo $i$ arkhivnoe delo. Terminy i opredeleniya: utv. Prikazom Rosstandarta ot 17.10.2013 № 1185-st [GOST R 7.0.8-2013. Record Keeping and Archival Business. Terms and Definitions: Approved by the Order of the Federal Agency on Technical Regulating and Metrology from 17 October 2013]. Moscow, Standartinform Publ. 12 p.

Zagidullina I.I., 2009. Mikheev M.Yu. Dnevnik kak egotekst (Rossiya, XIX-XX). M.: «Vodoley Publishers», 2007. 264 s. [Mikheev M.Yu. Diary as an Ego-Text (Russia, 19 ${ }^{\text {th }}-20^{\text {th }}$ ). Moscow: "Vodoley Publishers", 2007. 264 p.]. Uralskiy istoricheskiy vestnik [Ural Historical Journal], no. 3 (24), pp. 142-144.

Zaliznyak A.A., 2010. Dnevnik: k opredeleniyu zhanra [Diary: On the Definition of a Genre]. Novoe literaturnoe obozrenie [Russian Studies in Literature], no 6 (106), pp. 162-171.

Kon I.S., 1984. V poiskakh sebya. Lichnost i ee samosoznanie [In Search of Self. Personality and Self-Identity]. Moscow, Politizdat. 336 p.

Kosareva M.A., 2008. Setevoy dnevnik v kontekste teorii teksta ( $\mathrm{k}$ postanovke problemy) [The Networks Diary in the Context of Theory of Text (At the Statement of Question)]. Vestnik Chitinskogo gosudarstvennogo universiteta, no. 1 (46), pp. 69-74.

Krivolapova E.M, 2012. K voprosu o genezise zhanra dnevnika [To the Problem of Genesis of the Diary Genre]. Uchenye zapiski: elektronnyy nauchnyy zhurnal Kurskogo gosudarstvennogo universiteta [Scientific Notes: The Online Academic Journal of Kursk State University], no. 1 (21), pp. 188-196.

Kubaydulova A. Yu., 2015. Dnevnik K.I. Chukovskogo: k voprosu o khudozhestvennom svoeobrazii [Chukovsky's Diary: On the Issue About Artistic Originality]. Vestnik Samarskogo gosudartsvennogo universiteta [Vestnik of Samara State University], no. 2, pp. 120-125.
Lappo M.A., 2018. Samoidentifikatsionnyy diskurs russkoy elitarnoy yazykovoy lichnosti: dis. ... d-ra filol. nauk [Self-Identification Discourse of the Russian Elite Linguistic Personality. Dr. philol. sci. diss]. Novosibirsk. 515 p.

Leonova E.V., 2014. Kognitivnyy mekhanizm interiorizatsii $\mathrm{v}$ dnevnikovom diskurse [Cognitive Mechanism of Interiorization in the Diary Discourse]. Izvestiya Saratovskogo universiteta. Novaya seriya. Seriya: filologiya, zhurnalistika [Izvestiya of Saratov University. New Series. Series: Philology. Journalism], vol. 14 , no. 1, pp. 34-38.

Letyagin L.N., 2008. Lichnyy dnevnik: samosoznanie zhanra [Personal Diary: The Self-Awareness of Genre]. Izvestiya Rossiyskogo gosudarstvennogo pedagogicheskogo universiteta im. A.I. Gertsena [Izvestia: Herzen University of Humanities and Science], no. 56, pp. 56-67.

Lotman Yu.M., 2000. Semiosfera [Semiosphere]. Saint Petersburg, Iskusstvo SPb Publ. 704 p.

Matveeva Yu.V., 2014. Problema syuzheta v dokumentalnoy, biograficheskoy i avtodokumentalnoy proze [Problem of Plot in the Documentary, Biographical and Autodocumentary Prose]. Syuzhetologiya $i$ syuzhetografiya, no. 2, pp. 3-19.

Mikheev M.Yu., 2007. Dnevnik kak ego-tekst (Rossiya, XIX-XX) [Diary as an Ego-Text (Russia $19^{\text {th }}$ $\left.20^{\text {th }}\right)$ ]. Moscow, Vodoley Publishers. $264 \mathrm{p}$.

Salmanova I.F., 2017. Ispovedalno-dialogicheskaya priroda avtobiograficheskogo diskursa L.N. Tolstogo [Confessionaly - Dialogical Nature of Autobiographic Discourse of L.N. Tolstoy]. Nauka. Iskusstvo. Kultura [Science. Art. Culture], no. 1 (13), pp. 38-43.

Chistikova E.S., 2015. Mnemonicheskie teksty dnevnikov i memuarov: vremennaya udalennost kak tipologicheskiy kriteriy[Mnemonic Texts of Diaries and Memoirs: Time Distance as a Typological Criterion]. Vestnik Leningradskogo gosudarstvennogo universiteta im. A.S. Pushkina [Vestnik of Pushkin Leningrad State University], vol. 1, no. 3, pp. 134-140.

\section{SOURCES}

Tolstaya S. Lyubov i bunt. Dnevnik 1910 goda [Love and Rebellion. Diary of 1910]. Moscow, KoLibri Publ, Azbuka-Attikus Publ., 2013. 416 p.

Tolstoy L.N. Polnoe sobranie sochineniy: $v 90 t$. [Complete Works. In 90 Vols.]. Moscow, Rossiyskaya gosudarstvennaya biblioteka Publ., 2006. Vol. 32; Vol. 46; Vol. 47; Vol. 58. 


\section{Information about the Author}

Grigoriy V. Tokarev, Doctor of Sciences (Philology), Professor, Head of the Department of Document Studies and Stylistics of the Russian Language, Tula State Lev Tolstoy Pedagogical University, Prosp. Lenina, 125, 300026 Tula, Russia, grig72@mail.ru, https://orcid.org/0000-0002-2362-0902

\section{Информация об авторе}

Григорий Валериевич Токарев, доктор филологических наук, профессор, заведующий кафедрой документоведения и стилистики русского языка, Тульский государственный педагогический университет им. Л.Н. Толстого, просп. Ленина, 125, 300026 г. Тула, Россия, grig72@mail.ru, https://orcid.org/0000-0002-2362-0902 